\title{
EL CUADERNO DE CAMPO DE PALMIRA JAQUETTI (1895-1963) SOBRE LA MISIÓN M12 (BARCELONA, 1945) EN EL FONDO DE MÚSICA TRADICIONAL IMF-CSIC: INTRODUCCIÓN Y EDICIÓN
}

\author{
THE FIELD NOTEBOOK OF PALMIRA JAQUETTI (1895-1963) \\ ABOUT THE MISSION M12 (BARCELONA, 1945) \\ IN THE FONDO DE MÚSICA TRADICIONAL IMF-CSIC: \\ INTRODUCTION AND EDITION
}

\author{
Emilio Ros-Fábregas \\ Institución Milá y Fontanals \\ de Investigación en Humanidades - CSIC \\ emros@imf.csic.es \\ ORCID ID: 0000-0002-9032-1072
}

\section{Resumen}

En 2020 se celebra el $125 .^{\circ}$ aniversario del nacimiento de Palmira Jaquetti (1895-1963), compositora, poeta y folclorista cuyo nombre no aparece en los principales diccionarios de música. Llevó a cabo una ingente labor de recogida de ca. 10000 canciones tradicionales para la "Obra del Cançoner Popular de Catalunya" (1922-1936) - la mayoría siguen inéditas - y colaboró también con el Instituto Español de Musicología en la Misión M12 (1945) para recoger canciones de tradición oral en siete asilos de Barcelona. Las transcripciones de las $c a .450$ canciones recogidas de la Misión M12 y las fichas con los datos de las personas que las cantaron pueden consultarse en el portal web del Fondo de Música Tradicional IMF-CSIC (<https://musicatradicional.eu/source/130>), pero el cuaderno de campo en el que Jaquetti anotó las vicisitudes de esa misión permanecía inédito. Este cuaderno, que se transcribe en esta aportación, es particularmente valioso por su interés etnomusicológico y social - al describir aspectos de la Barcelona de posguerra-, y desde el punto de vista literario como muestra de la prosa clara, sencilla, elegante y expresiva de una mujer extraordinaria.

\section{Palabras clave}

Palmira Jaquetti (1895-1963), cuaderno de campo, música y mujeres, Obra del Cançoner Popular de Catalunya, Fondo de Música Tradicional IMF-CSIC, Instituto Español de Musicología, misiones folclóricas, Barcelona.

\begin{abstract}
In 2020 we celebrate the 125th anniversary of Palmira Jaquetti (1895-1963), a composer, poet and folklorist whose name does not appear in the main music dictionaries. She carried out an important task of collecting $\mathrm{ca}$. 10.000 Catalan folksongs for the project "Obra del Cançoner Popular de Catalunya" (1922-1936) - most of them unpublished - and collaborated with the Instituto Español de Musicología in the Misión M12 (1945) to collect songs of oral tradition in seven charity nursing homes in Barcelona. The transcriptions of the $c a .450$ songs collected in the Misión M12 and the informants' cards of the people who sang them can be consulted in the website of the Fondo de Música Tradicional IMF-CSIC (<https://musicatradicional.eu/source/130>), but the field notebook where Jaquetti annotated the vicissitudes of the mission remained unpublished. This notebook, transcribed here, is particularly valuable, owing to its ethnomusicological and social interest - describing aspects of post Spanish Civil War Barcelona - and, from the literary point of view, as an example of clear, straightforward, elegant, and expressive prose of an extraordinary woman.
\end{abstract}

\section{Keywords}

Palmira Jaquetti (1895-1963), field notebook, women and music, Obra del Cançoner Popular de Catalunya, Fondo de Música Tradicional IMF-CSIC, Instituto Español de Musicología, folklore, Barcelona. 
En el Año Palmira Jaquetti (2020-2021)

\section{INTRODUCCIÓN}

Entre abril y septiembre de 1945, la compositora, poeta y folclorista Palmira Jaquetti (1895-1963) desarrolló la Misión M12 en Barcelona para el Instituto Español de Musicología del Consejo Superior de Investigaciones Científicas (CSIC) como parte de las "misiones" que se realizaron por toda España, entre 1944 y 1960, para recoger música de tradición oral. ${ }^{1} \mathrm{El}$ propósito de la presente aportación es contextualizar la transcripción del cuaderno de campo, hasta ahora inédito, en el que Jaquetti describió las vicisitudes durante su trabajo de recogida de $c a .450$ canciones en siete asilos de Barcelona. Este cuaderno es particularmente valioso por su interés etnomusicológico y social - al describir aspectos de la Barcelona de posguerra-, y desde el punto de vista literario para acercarnos al estilo claro, sencillo y expresivo de su autora.

Jaquetti no aparece en los principales diccionarios de música y es una persona desconocida para el gran público. ${ }^{2}$ Participó en las misiones de la Obra del Cançoner

${ }^{1}$ Higini Anglès creó el Instituto Español de Musicología-CSIC en Barcelona en 1943. Los materiales recogidos en las 65 misiones y 67 cuadernos de concursos organizados por su sección de folclore entre 1944 y 1960 se conservan actualmente en el Fondo de Música Tradicional IMF-CSIC y pueden consultarse a través de su web: $<$ https://musicatradicional.eu $>$

2 Sobre la vida y obra de Palmira Jaquetti y la bibliografía acerca de ella, véase el portal web Any Palmira Jaquetti, creado en 2020 por la Generalitat de Catalunya para celebrar el 125 aniversario de su nacimiento: $<$ https://cultura.gencat.cat/ca/temes/commemoracions/2020/anypalmirajaquetti/palmira-jaquetti/>; las fechas oficiales del "Any Palmira Jaquetti" son del 2 de marzo de 2020 al 8 de mayo de 2021. Véanse, entre otros, los siguientes estudios sobre Jaquetti: Roser Matheu, Quatre dones catalanes (Barcelona: Fundació Salvador Vives Casajuana, 1972), pp. 171-192; Simon Furey, "Palmira Jaquetti i Isant, Catalan folk song collector (1895-1963)", Estudos de Literatura Oral, 13-14 (2007-08), pp. 159-174; Maria dels Àngels Subirats Bayego, Josefina Roma, Salvador Rebés y Joan de la Creu Godoy Tomás, "Palmira Jaquetti", Revista d'Etnologia de Catalunya, 21 (2002), p. 168; Josefina Roma, "La dona en les cançons tradicionals a la Ribagorça" Ripacurtia, 3 (2005), pp. 85-108; Josefina Roma, "Palmira Jaquetti y la investigación del folklore musical", Temas de Antropología Aragonesa, 18 (2011), pp. 195-210; Josefina Roma, "La descoberta de la músi-
Popular de Catalunya (1922-1936), para las que recogió en papel alrededor de 10000 canciones - la mayor parte de ellas inéditas - , pero su polifacética figura y obra merecen ser estudiadas en profundidad. ${ }^{3}$ Fue una mujer avanzada para su época, licenciada en Filosofía y Letras por la Universidad de Barcelona con Premio Extraordinario (1927), y con estudios musicales en el Conservatorio de Barcelona, y ejerció como profesora de historia del arte y francés en diversos institutos. Se casó con un pintor belga que inicialmente la acompañó en sus viajes de recogida de canciones por Cataluña (1927-1930), pero él no apoyaba su carrera literaria y, al caer ella gravemente enferma con poliartritis reumatoide en 1934, la abandonó y el matrimonio acabó en divorcio. A partir de 1937 Jaquetti, recuperada parcialmente de su enfermedad, prosiguió su actividad en Barcelona como maestra, poeta y recolectora de canciones, llegando también a presentar algunos trabajos de investigación en congresos internacionales. ${ }^{4}$

ca tradicional del Pirineu. Palmira Jaquetti i l'obra del Cançoner Popular de Catalunya", Annals del Centre d'Estudis Comarcals del Ripollès / Íbix 7 (2012), pp. 231-237; y Marta Grassot Radresa, "Cartes per recordar. Palmira Jaquetti i la recerca musical de camp", Revista Musical Catalana (17 d'abril de 2020): <http://www.revistamusical.cat/cartes-per-recordar-palmira-jaquetti-i-la-recerca-musical-de-camp/>.

3 De su obra poética, en parte todavía inédita, destacan las siguientes ediciones publicadas: L'estel dins la llar (Barcelona: Edicions Oasi, 1938); Roda de Nadals (Barcelona: Studium, 1949); i Poema de Santa Llúcia (Barcelona: Edición de la autora, 1961). También publicó traducciones de teatro y poesía franceses: Alfred de Musset, Carmosina (Barcelona: Biblioteca Popular de "L'Avenç", 1926); y, del mismo autor, La nit veneciana (Barcelona: Biblioteca Popular de "L’Avenç", 1926); Gérard de Nerval, Jemmy, La Novel·la Estrangera, 18 (Valls: E. Castells, [1925?]; y, del mismo autor, Emilia. La mà encantada, La Novel·la Estrangera 28 ([Valls]: E. Castells, [1925]); y Selecta de poetes medievals (Barcelona: Biblioteca Popular de "L'Avenç", 1926). Como arreglista y compositora publicó: Mis canciones (Barcelona: Juventud, 1943); Trenta cançons nadalenques per a cant $i$ piano harmonitzades (Barcelona: J. García Gelabert, 1952); Cançons de caramelles per a chor d'homes, quartet vocal o chor mixte a dues, tres i quatre veus (Barcelona: J. García Gelabert, 1953); Goigs de Sant Pelegrí Arties. Lletra i música (Barcelona: Obradors Gràfics Mariano Galve, 1953); Selección de canciones navideñas: originales y populares, dos cuadernos (Barcelona: J. Parés, 1954 y 1955); e Himnos ([Barcelona:] J. M. Parés, s.f.).

${ }^{4}$ A raíz de su participación en congresos internacionales, Palmira Jaquetti publicó tres artículos: "La comptina", en Atti 
Un trágico accidente de coche en 1963 acabó con su vida. Tal como afirma la presentación de la página web dedicada al 125 aniversario de su nacimiento:

Palmira Jaquetti es una de las muchas mujeres que, desde un anonimato todavía vigente, contribuyó a mejorar el nivel cultural del país a partir de sus inquietudes musicales, literarias, pedagógicas y humanísticas en general. Como mujer de una época en la que era difícil ser escuchada y valorada en el mundo intelectual y cultural, representa un paradigma de tantas otras mujeres, también anónimas, que contribuyeron a construir un modelo de país. ${ }^{5}$

Jaquetti recogió 448 canciones (259 con música y 189 con solo el texto) en siete asilos de Barcelona que, en el orden en que los visitó, son los siguientes: Casa de la Caridad (c/ Montalegre), Hermanitas de los Pobres (c/ Caspe), Hermanitas de los Pobres del barrio de Gracia (c/ Sant Salvador), Hermanitas de los Pobres (c/ Borrell), Asilo de Nuestra Señora de Port (c/ del Cistell), Casa de la Maternidad (c/ Ramelleres) y Asilo del Parque (c/ Wellington). Las fichas recogidas por Jaquetti de estas piezas y de las 52 personas asiladas que las transmitieron (11 hombres y 41 mujeres procedentes de diversas localidades de la geografía española) constituyen la Misión M12, cuyos materiales se pueden consultar en acceso abierto en

dell'VIII Congresso Internazionale di Studi Romanzi. Firenze, 3-8 aprile 1956 (Florencia: Sansoni, 1960), vol. 2, pp. 567-599; "Contribution à la syntaxe de l'aranais", en Actas do IX Congresso Internacional de Linguística Românica (Universidade de Lisboa 1959), editado por Manuel Lopes de Almeida (Lisboa: Centro de Estudos Filológicos, 1961), pp. 377-393; y “Apport à l'hydronoymie du Val d'Aran", en VI. Internationaler Kongress für Namenforschung (München, 24.- 28. August 1958), ed. Gerhard Rohlfs y Karl Puchner (Munich: Verlag der Bayerischen Akademie der Wissenschaften in Kommission, 1961), vol 3, pp. 437-443.

5 "Palmira Jaquetti és una de les moltes dones que, des d'un anonimat encara vigent, van contribuir a millorar el nivell cultural del país a partir de les seves inquietuds musicals, literàries, pedagògiques i humanístiques en general. Com a dona d'una època en què era difícil ésser escoltada i valorada en el món intel-lectual i cultural, representa un paradigma de tantes altres dones, també anònimes, que van contribuir a construir un model de país", en página de inicio de la web Any Palmira Jaquetti: $<$ https://cultura.gencat.cat/ca/temes/commemoracions/2020/ anypalmirajaquetti/inici/> (consulta: 17/11/2020; traducción del autor). el portal web / base de datos del Fondo de Música Tradicional IMF-CSIC. ${ }^{6}$

De la Misión M12 permanecían inéditos todavía: 1) el cuaderno de campo de Jaquetti que aquí comento y edito ("Misión $\mathrm{N}^{\circ} 12$. Guión y comentario de mis actividades en la recopilación de canciones encomendada por el Instituto de Musicología. Verano 1945") en el que la investigadora describió las vicisitudes de la misión; y 2) nueve cartas de presentación a otras tantas instituciones de beneficencia que algunas autoridades escribieron a Jaquetti para facilitarle su labor. El contenido del cuaderno se transcribe al final de este estudio. El cuaderno, tamaño cuartilla, con 21 páginas manuscritas sin numerar, es un testimonio muy valioso sobre las dificultades que tuvo Jaquetti para acceder a los asilos, las personas que le ayudaron y, sobre todo, sus impresiones acerca de estas instituciones y de algunas de las personas que le proporcionaron las canciones, utilizando una prosa sencilla y directa que muestra una gran sensibilidad. ${ }^{7}$

Jaquetti, como participante destacada en la recogida de canciones para la Obra del Cançoner Popular de Catalunya (1922-1936), tenía una gran experiencia por ser seguramente la persona que recogió más piezas para ese magno proyecto. Ella comenta en el cuaderno que, debido a las restricciones que tuvo, no le fue posible tomar fotos

${ }^{6}$ Emilio Ros-Fábregas y Ascensión Mazuela-Anguita, "MISIÓN M12", Fondo de Música Tradicional IMF-CSIC, ed. Emilio Ros-Fábregas, <https://musicatradicional.eu/source/130> (consulta: 17/11/2020). Sobre este Fondo (con más de 23.000 piezas de tradición oral accesibles en línea), en el contexto de la investigación que lleva a cabo el grupo "Música y sociedad" de la Institución Milá y Fontanals de Investigación en Humanidades del CSIC (IMF-CSIC) en Barcelona, véase Emilio Ros-Fábregas, "Capacidad transformadora de las Humanidades Digitales en el ámbito de la Musicología: las plataformas digitales de la IMF-CSIC Fondo de Música Tradicional y Books of Hispanic Polyphony", en Musicología en web. Patrimonio Musical y Humanidades Digitales, editado por María Gembero-Ustárroz y Emilio Ros-Fábregas (Kassel: Reichenberger, en prensa).

${ }^{7}$ El cuaderno de Palmira Jaquetti no se encontraba con los materiales de la Misión M12, sino que estaba desubicado en una carpeta miscelánea y equivocadamente asociado con Ibiza. Durante el proceso de ordenación y catalogación que he realizado de los materiales de las misiones del Instituto Español de Musicología-CSIC, localicé este cuaderno y lo incorporé al nuevo archivador del Fondo de Música Tradicional IMF-CSIC, Misión M12: <https://musicatradicional.eu/source/130>. 
para la Misión M12, en contraste con lo que había hecho para el Cançoner:

Este lugar lo destinaba para fotos, si hubieran sido posibles, tal como lo hice en mis misiones de colectora al Pirineo, donde mi actividad trajo 10.000 fichas al Cancionero Catalán y cantidad enorme de fotos de cantores en su ambiente. ${ }^{8}$

Jaquetti tampoco pudo tomar registros fonográficos de algunos informantes que consideraba interesantes. Ella recomendó a Francesc Pujol - colaborador de las misiones del Instituto Español de Musicología-CSIC y que había sido responsable también de las misiones del Cançoner Popular de Catalunya- que se tomaran registros fonográficos de dos informantes en particular, pero no se llegaron a realizar. Jaquetti comenta al respecto:

El maestro Pujol había ya recibido mi encargo y prometió hacer acudir a los cantores señalados. Especialmente a José Díaz, de la casa de Caridad, y a la cantora de las Hermanitas de la c[alle] Caspe de quien hablo en su debido lugar. Me duele que no se realicen esas pruebas. La mujer, también el hombre, valen la pena. ${ }^{9}$

${ }^{8}$ Palmira Jaquetti, "Misión $\mathrm{N}^{\mathrm{o}} 12$. Guión y comentario de mis actividades en la recopilación de canciones encomendada por el Instituto de Musicología. Verano 1945”, p. 2. Aunque el repertorio de tradición oral que Jaquetti recogió para el Cançoner Popular de Catalunya sigue básicamente inédito, las Memorias que redactó de cada una de esas otras misiones en las que participó se han publicado en Josep Massot i Muntaner, ed., Materials de l'Obra del Cançoner Popular de Catalunya, 21 vols. (Barcelona: Fundació Rabell i Cibils y Publicacions de l'Abadia de Montserrat, 1926-2011), vols. 6, 7, 9, 10, 11, 12, 14, 16 y 20. Véase también, sobre una misión de Palmira Jaquetti en el Hospital de Sant Pau y en Tona (1936-37), Josep Massot i Muntaner, "Noves aportacions a l'Obra del Cançoner Popular de Catalunya", A la ciutat dels llibres, Tercera Sèrie (Barcelona: Publicacions de l'Abadia de Montserrat, 2019), pp. 61-74.

9 Jaquetti, "Misión No 12 . Guión y comentario de mis actividades", p. 3. En el reverso de una cuartilla con un borrador de "Índice de cantores" (reproducido en "Otros documentos" en la web de la Misión M12), Jaquetti anotó: “Díaz / Fonográficas 46, 47, 48b, 48c, 76, 85", para indicar su interés por grabar esas piezas. Hay dos informantes de la Misión M12 con apellido Díaz y en esta inscripción Jaquetti se refiere a Manuel Díaz Márquez. En la ficha M12-046, Jaquetti, al final de la transcripción incompleta de la melodía cantada por este informante, anotó: "No puedo continuar, este hombre necesita un aparato fono-
La muerte de Francesc Pujol en diciembre de ese mismo año 1945 truncó una de las conexiones directas entre los proyectos de recogida de canciones del Cançoner Popular de Catalunya y de las misiones del CSIC, aunque algún aspecto del sistema de Pujol para clasificar géneros musicales populares - descrito póstumamente en un artículo publicado en Anuario Musical - fue adoptado inicialmente para las misiones del Instituto Español de Musicología-CSIC. ${ }^{10}$

gráfico"; en la ficha del texto de otras piezas del mismo informante (M12-41-2, 48b, 48c, 76, 109, 113, 114) anotó: "fonografiar". Véase la página de dicho informante: $<$ https://musicatradicional.eu/ca/informant/1214> y, más abajo, los comentarios de Jaquetti sobre los dos informantes de apellido Díaz. La mujer "cantora de las Hermanitas de la calle Caspe" a la que Jaquetti hace referencia es Andrea Villanua Malo, una cantora ciega $<$ https://musicatradicional.eu/informant/4570>, que no debe confundirse con Angelina, otra cantora ciega de la Casa de la Caridad, Ángela Agudo Pintado <https://musicatradicional. eu/informant/221>, de la que también habla Jaquetti.

${ }^{10}$ Francesc Pujol, "Clasificación de las melodías populares. Metodología”, Anuario Musical, 1 (1946), pp. 19-29. En ese primer volumen de Anuario Musical, pp. 239-240, en la sección anónima "Actividades del Instituto Español de Musicología", se destacó lo siguiente: "El maestro Francisco Pujol comenzó los índices de todas las canciones, sus asuntos y las clasificó convenientemente. Hizo un croquis detallado de la forma métrica de cada canción y de los elementos tonales que caracterizan a cada melodía"; y más adelante: "En vista a ulteriores trabajos, se procede también a una nomenclatura de los Romances tradicionales tan abundantes en España. Sobre este tema, don Francisco Pujol redactó un folleto, Romances tradicionales y canciones narrativas (Barcelona, 1945), especie de guión para los que se dediquen a recogerlos. Para redactarlo se tuvo a la vista, como modelo y fuente de romances, el similar publicado por doña María Goyri de Menéndez Pidal, que lleva por título Romances que deben buscarse en la tradición oral'. Se mencionaban también las 40 piezas recogidas en los asilos de Madrid por Magdalena Rodríguez Mata "y las 400 que doña Palmira Jaquetti ha encontrado en los de Barcelona en labios de los asilados de centros similares".

Entre 1944 y 1955, Marius Schneider, antiguo director del Phonogramm-Archiv de Berlin, fue colaborador permanente y director de la sección de folclore del Instituto Español de Musicología. En aquellos años, entre los colaboradores de esa sección en Barcelona estuvieron José Antonio Donostia, Arcadio de Larrea, Josep Romeu Figueras y Joan Tomàs Parés, cuya labor, como la de Jaquetti, tampoco ha sido suficientemente reconocida. Higini Anglès instó en varias ocasiones a que el Orfeó Català continuara con las misiones de la Obra del Cançoner Popular de Catalunya. 
De las nueve cartas de presentación que se conservan de la Misión M12, solo una surtió el efecto deseado para que Jaquetti pudiera acceder a la institución correspondiente a recoger canciones: la dirigida a la madre superiora de la Hermanitas de los Pobres de la calle Borrell, ${ }^{11}$ pero - tal como relata Jaquetti en su cuaderno - fue conminada a cesar en su actividad muy pronto. ${ }^{12}$ Las otras ocho cartas de presentación mecanografiadas están firmadas el 28 de marzo de 1945 por Diego Ramírez Pastor, Diputado Ponente de Beneficencia de la Diputación de Barcelona, y van dirigidas a responsables de instituciones benéficas dependientes de la Diputación. Hay además un "Saluda" que acompañaba estas cartas dirigido "a la distinguida Sra. D Palmira Jaquetti", en el que Ramírez "se complace en adjuntarle diversas cartas de presentación dirigidas a los respectivos Superiores o Directores de las Instituciones benéficas que dependen o se relacionan con esta Diputación Provincial, para que puedan serle facilitados los datos que

${ }^{11}$ El sobre tiene remite del "Gobierno Civil / Junta Provincial de Beneficencia / Barcelona", dirigido a la "Rvda. Madre Superiora de las Hermanitas de los Pobres / Borrell 150 / Ciudad". El escrito, también con membrete "Gobierno Civil / Junta Provincial de Beneficencia / Barcelona / No 454", dirigido a la "Rvda. Madre Superiora de las Hermanitas de los Pobres. Ciudad", dice: "Habiéndose dirigido al Excmo. Sr. Gobernador Civil, Presidente de esta Junta, Doña Luisa Jaquetti, solicitando facilidades para el cumplimiento de la misión que como Delegada del Instituto de Musicología se le tiene encomendada, esta Junta, en nombre de S. E., ruega a Vd. se sirva darle toda clase de facilidades para llevar a cabo tal fin. Dios guarde a Vd. muchos años. Barcelona, 17 de abril de 1945. El Vicepresidente [Sello y firma]".

12 Jaquetti, "Misión No 12. Guión y comentario de mis actividades", p. 13-14: “Tengo que añadir que la decisión absurda y conminadora de cesar en el mismo día en que me fue dada la orden obedeció a las necesarias preguntas de edad nombre y condición con que llenar mi ficha. Y quiero aún consignar, aunque inmodestamente, mi amabilidad y conocimiento del mundo, de los niños y de los viejos, y mi falta de curiosidad, aunque soy mujer. Con ello quiero significar la ausencia de otras preguntas y otros intereses más que los que se me encomendaron. Es más: casi nunca lleno la ficha sino al cabo de una o dos canciones, para no ser brusca y llevar las preguntas con los elogios de lo que acabo de apuntar". Hay que tener en cuenta que - a pesar del tacto y buenas intenciones de Jaquetti- en época de posguerra podía resultar muy problemático preguntar datos personales y de origen geográfico, lo que explicaría las resistencias que encontró. Hoy en día los cuestionarios de música tradicional suelen solicitar una autorización firmada por el informante para garantizar la cesión protegida de sus datos personales. desea obtener." El breve texto mecanografiado de esas ocho cartas de presentación es idéntico, cambiando el nombre e institución de los/las destinatarios/-rias: ${ }^{13}$

Tengo el gusto de presentarle a la Sra. Palmira Jaquetti, Catedrático, la cual por haber sido nombrada Delegada del Instituto de Musicología, desea obtener determinados datos relacionados con la misión que le ha sido confiada, que ruego puedan serle facilitados.

\section{Respetuosamente le saluda. Diego Ramírez Pastor Barcelona, 28-3-45}

El motivo por el cual estas cartas no fueron útiles lo explica la propia Jaquetti en su cuaderno, al tiempo que revela también que, además de los siete asilos en los que recogió repertorio, exploró sin éxito otras instituciones para niños y discapacitados:

Incluyo algunas cartas que no me fueron de utilidad, obtenidas en mi trabajo preliminar. Esos asilos fueron consultados por mí y me dijeron no tener más que niños o incapacitados. Intenté aún el Manicomio. Pero aparte aquellos hombres como sombras de hombre, que pasean con un guía delante porque no saben querer ni la más mínima voluntad de obrar rige sus almas, no fue hallado ningún recluso con talante ni facultades cantoras, a pesar de mi valimiento en la caza. ${ }^{14}$

Las cartas de presentación que fueron más eficaces no se conservan en la IMF-CSIC y las proporcionó el

13 Los destinatarios de esas ocho cartas son: 1) Rvda. Madre Superiora del Orfanato de San José, calle Provenza 388, Barcelona; 2) Rvda. Madre Superiora del Hogar para Huérfanos de la Guerra, calle Urgel 262, Barcelona; 3) Sr. Director del Colegio Infantil de San Julián de Vilatorta, calle Urgel 112, Barcelona; 4) Rvda. Madre Superiora de las Religiosas Misioneras de 'Cristo Rey', Avenida Vallvidrera 4, Barcelona; 5) Sra. Directora del Colegio Infantil de Las Fonts de Tarrasa; 6) Rvda. Madre Superiora del Colegio Albergue de San Antonio, Consejo de Ciento 437, Barcelona; 7) Rvdo. Padre Superior del Colegio 'Villa Salud', San Feliu de Llobregat; 8) Dr. Dn. José M Petit Freixas, Director del Sanatorio Infantil 'Narcisa Freixas', La Garriga.

${ }^{14}$ Jaquetti, "Misión No 12 . Guión y comentario de mis actividades", p. 18-19. Además, en su entusiasmo por recopilar este repertorio oral, Jaquetti afirma: "Pero queda todavía un filón no explotado. Esa beta inédita es la Cárcel, donde hombres y mujeres en el perfecto ejercicio de su memoria están relativamente inactivos y por ello en perfecto estado de memoria, y lo que es más, inclinados a confiar al canto sus miserias". 
Ayuntamiento, por mediación del barón de Esponellà, Epifani de Fortuny i Salazar (Barcelona, 1898-Barcelona, 1989), teniente de alcalde y presidente de la Ponencia de Beneficencia en aquellas fechas; Jaquetti menciona que Higini Anglès intervino también para facilitarle el acceso al asilo de las Hermanitas de los Pobres de la calle Caspe.

Palmira Jaquetti destaca en su cuaderno las personas que consideró más interesantes como cantantes, con comentarios muy precisos y llenos de ternura. Contrastando la información del cuaderno con las fichas de las piezas y de los informantes de la Misión M12, es posible identificar sus nombres completos. De la Casa de Caridad Jaquetti destaca, entre los hombres, los dos de apellido Díaz; ${ }^{15}$ entre las mujeres, menciona a Hipólita ${ }^{16}$ y Angelina. Esta última era ciega y Jaquetti recordaba haberla visto en su niñez por las calles de Barcelona:

...una cieguecita que recuerdo haber conocido en mi niñez, cantadora callejera, pequeña, suave, dulce, poquita cosa, con los ojos cerrados que no miran a ninguna parte, eternamente hundidos en sus órbitas. En el ojo derecho tiene una perla negra que le arrastra del párpado. No nació ciega. Un médico de aldea le trató los ojos con nitrato de plata y quedó con vida y manos para cegar otras víctimas el mediquillo. Pero Angelina hubo de sumirse en un sepulcro de tinieblas y de miseria que le ha dado la calle como nodriza y mentora, el asilo como premio final. Sus canciones pertenecen casi todas a la más absurda expresión de plebeyismo y decadencia. Todos los couplets están representados en su memoria-archivo. Todas las barbaridades musicales fueron servidas por ella a boca de jarro, a la puerta del

15 Jaquetti, "Misión № 12. Guión y comentario de mis actividades", pp. 5-6: "Entre los hombres de la primera casa [Casa de la Caridad] hay dos viejecitos llamados Díaz, uno cocinero [José Díaz Sanz-Gil] en su vida por el mundo, el otro el más dicharachero andaluz que darse pueda [Manuel Díaz Márquez]. Han cantado mucho. Me esperaban ya de un día para otro con algo nuevo, especialmente el cocinero, menos soñador, con su pequeña barbilla, su aureola blanca y su caballerosidad. El otro Díaz, que es como un tío-vivo, como peonza inquieta, le saca chiste a su brazo paralítico hasta que la hermana no puede por menos que reñirle mientras escapa en su risa, como cogida en pecado. Todas las canciones del Díaz andaluz deberían fonografiarse. Es una fuente viva de salmodias y melodías y las canta muy bien. Se conduele continuamente de su juventud perdida, pero no tiene por ello menos sal. Su tono suave y su canto en sordina resultan, quizás, mejores sin congestionamiento ni voceos".

16 Véase la ficha de Hipólita Olano Mardones en $<$ https:// musicatradicional.eu/informant/3201>. mercado, donde las cándidas muchachitas de servicio aprenden su repertorio. Ella goza detallando esa felicidad suya, que se vertía en canto, como a la sombra de un árbol, bajo la copiosa frondosidad de las guitarras y bandurrias que la coreaban y que acompañaban su pobre alma, el alma que presentía vagamente su cielo. ${ }^{17}$

Es probable que Andrea Villanua Malo, otra "cantora" ciega, sea la anónima mujer del asilo de las Hermanitas de los Pobres de la calle Caspe que Jaquetti describe así:

Entre ellas una pequeña mujercita con cara de niña [espacio dejado en blanco, tal vez para el nombre], que canta maravillosamente y esconde sus años en un gracejo que la cubre como el fleco del mantón de algo cambiante y divino y así la devuelve a la niñez. Sus canciones deberían ser fonografiadas. En algunas escapa a ritmo y a pentagrama, en una continua creación juguetona y alegre como un cascabel. ${ }^{18}$

Jaquetti comenta su actividad frenética de recolección de material e incluso nos transporta poéticamente a los desagradables olores de diversas estancias de los asilos y a sus vetustos sillones:

He copiado en el costurero, en una mesa llena de alfileres. En el comedor, sumergido en el olor eterno de las grasas y estofados. En la fregadera, visitada por todos los cubos de la casa; los sábados en la enfermería, donde la vida declina sobre blancas almohadas y los sillones se invalidan a fuerza de sostener la invalidez. ${ }^{19}$

La honda impresión que dejan en Palmira Jaquetti las visitas a estas instituciones de caridad es también reflejo de la miseria que "acumula sus trofeos" en la Barcelona gris de posguerra.

He visto y sentido mucho y honradamente en esos lugares donde la miseria acumula sus trofeos. Llagas en el

17 Jaquetti, "Misión N N 12. Guión y comentario de mis actividades”, pp. 6-8. Véase la ficha de Ángela Agudo Pintado $<$ https://musicatradicional.eu/informant/221>.

18 Jaquetti, "Misión No 12 . Guión y comentario de mis actividades", pp. 9-10. Véase la ficha de Andrea Villanua Malo, $<$ https://musicatradicional.eu/informant/4570>, de la que Jaquetti dice: "Campo de Cariñena [Zaragoza] y Navarra, con un hermano también ciego, eran recorridos siguiendo fiestas y ferias. Se acompañaba de la guitarra. Ahora no podría tocar porque tiene la mano derecha imposibilitada".

19 Jaquetti, "Misión No 12 . Guión y comentario de mis actividades", p. 10. 
alma y en el cuerpo aquejan a los infortunados pobres. Se pueden apurar los cálices del dolor y de una sola vez gustar muchos sufrimientos. ${ }^{20}$

Jaquetti tuvo acceso solo una vez a las Hermanitas de los Pobres de Gracia y también a las Hermanitas de los Pobres de la calle Borrell por un breve espacio de tiempo. Las dos últimas instituciones visitadas por Jaquetti fueron el Asilo de Nuestra Señora de Puerto y la Casa de la Maternidad, que ella se esfuerza en diferenciar de las instituciones anteriores. De la primera dice que "No recibe a sus clientes para morir, sino como en un albergue, como un brazo hospitalario que cobija por un tiempo. Por ello he encontrado lo mejor en ese Asilo"; ${ }^{21}$ de allí destaca a la costurera abulense Rosa Lefler, de la que recogió treinta y tres canciones:

Rosa Lefler mujer todavía en el uso de sus fuerzas, gran cantarina, bordadora de oficio, ha venido a parar aquí y sus cantos a mis cuadernos. Es un tesoro de añoranza, de simplicidad popular de pretérita felicidad. Cantó y aprendió todo cuanto oía junto a su máquina de bordar. Cantó y vivió su juventud. Ahora ha cantado a la fuerza y se ha hecho un momento feliz en su gran desolación. Le he pagado algo. Vuelve a recordar. Y durante muchos días Rosa Lefler ha llenado mis cuadernos.22

De la Casa de la Maternidad, Jaquetti recomienda que se visite periódicamente para recoger canciones y comenta: "La nueva madre está siempre pendiente de la voz lejana del hijo, que la llama como la misma conciencia, y ese clima da a su canción un hálito singular". ${ }^{23}$ En el Asilo del Parque, donde le dieron toda clase de facilidades, la informante Victoria Sáenz Garijo le proporcionó casi 200 piezas, aunque muchas de ellas solo con el texto. ${ }^{24}$

20 Jaquetti, "Misión N N 12. Guión y comentario de mis actividades", pp. 14-15.

${ }^{21}$ Jaquetti, "Misión No 12 . Guión y comentario de mis actividades", p. 15.

${ }^{22}$ Jaquetti, "Misión No 12 . Guión y comentario de mis actividades", pp. 15-16. Véase la ficha de Rosa Lefler Herradura en el siguiente enlace $<$ https://musicatradicional.eu/informant/2358 $>$.

${ }^{23}$ Jaquetti, "Misión No 12 . Guión y comentario de mis actividades", p. 17.

24 Victoria Sáenz Garijo de 86 años, natural de Cervera del Río Alhama (La Rioja), llevaba viviendo 60 años en Barcelona; véase el enlace $<$ https://musicatradicional.eu/informant/3985>. Jaquetti, "Misión $\mathrm{N}^{\mathrm{o}} 12$. Guión y comentario de mis actividades", pp. 19-20, comenta sobre ella lo siguiente: "Ese es el caso de Victoria, que visitaba con mucha frecuencia para darle tiem-
El repertorio musical recogido por Jaquetti en la Misión M12, la mayor parte en español (solo dieciséis piezas en catalán), es muy diverso en cuanto a géneros musicales y procedencia geográfica; ${ }^{25}$ constituye una foto fija de la memoria sonora de numerosos inmigrantes llegados a Barcelona desde el resto de España durante la primera mitad del siglo XX. Más allá del valor intrínseco de las melodías y textos de tradición oral recogidos por Palmira Jaquetti en los asilos de Barcelona, el cuaderno en el que describe sus impresiones es particularmente valioso como documento sociológico e histórico sobre la ciudad. Al igual que había hecho en las crónicas en catalán de sus misiones de recogida de canciones para la Obra del Cançoner Popular de Catalunya, Jaquetti muestra en este cuaderno una enorme sensibilidad como escritora, con una prosa —en este caso en castellano - clara, sencilla, elegante y expresiva.

La conmemoración en 2020-21 del 125 aniversario del nacimiento de Palmira Jaquetti es una magnífica oportunidad para dar a conocer a la ciudadanía su labor realizada en múltiples direcciones. La lectura de la edición que se incluye a continuación del cuaderno de campo de la Misión M12 conservado en el Fondo de Música Tradicional IMF-CSIC nos acerca a la personalidad de esta mujer extraordinaria.

\section{EDICIÓN DEL CUADERNO DE CAMPO (1945) DE PALMIRA JAQUETTI ${ }^{26}$}

\section{[Tapa] \\ Misión N 12 / Guión y comentario / de mis actividades en la / recopilación de canciones / encomendada por el Instituto / de Musicología. / Verano 1945 / P. Jaquetti.}

\section{[p.1]}

Costó mucho poner en movimiento los engranajes auxiliares a mi tarea. Visitas, explicaciones y telefonazos

po a recordar. Ha sido incansable, buena, sufrida. Fue persona pudiente, con tienda puesta en barrio muy denso y popular. Recogió toda canción oída, toda letra y cuarteta, toda basura. Y con tanto material, poco cuesta levantar lo mejor y dejar la paja".

${ }^{25}$ El repertorio relacionado con Latinoamérica se debe al informante José Díaz-Sanz-Gil, que había participado en la Guerra de Cuba y había viajado por todo el mundo como cocinero de barco.

26 Este cuaderno tamaño cuartilla, con tapas blandas anterior y posterior, tiene 11 hojas sin numerar, de las que Palmira Jaquetti rellenó a mano todas sus páginas [1-21], excepto la últi- 
resultaban estériles. Tuve que hacerme con cartas de presentación de una entidad menos lejana a funciones de Beneficencia que el Instituto de Musicología. Y más eficaz para penetrar en el seno de esos inmensos lugares donde la vida se aleja y apaga lentamente.

Mi amistad profesional con el Sr/ $1^{\text {er }}$ Diputado de Beneficencia de la Diputación de Barcelona, Sr. Ramírez, ${ }^{27}$ me puso ya sobre camino seguro en lo que concierne a establecimientos que dependen de aquella institución.

\section{[p. 2]}

(Este lugar lo destinaba para fotos, si hubieran sido posibles, tal como lo hice en mis misiones de Colectora al Pirineo, donde mi actividad trajo 10.000 fichas al Cancionero Catalán y cantidad enorme de fotos de cantores en su ambiente).

También quiero hacer constar mi sentimiento por no poder continuar la misión en las Hermanitas de los Pobres, ambas secciones y mi voz de alerta por algunos casos muy notables que no se com- [p.3]pletan ni transcriben sino con placa fonográfica.

El Maestro Pujol ${ }^{28}$ había ya recibido mi encargo y prometió hacer acudir a los cantores señalados. Especial-

ma. Una pegatina blanca añadida en la parte inferior de la portada dice: "JAQUETTI, Palmira. Misión nº 12 / Ibiza [sic]: 1945. / Cuaderno de campo. / (Carpeta IV, n ${ }^{\circ} 3$ )". La mención a "Ibiza" en esa etiqueta es un error; este cuaderno no tiene nada que ver con Ibiza. Cuando me incorporé a la IMF-CSIC a mediados de 2009, este cuaderno no se encontraba en el archivador de la Misión M12 con las fichas de informantes y de las melodías recogidas por Palmira Jaquetti en los asilos de Barcelona, sino que estaba desubicado en una "Carpeta IV" junto con otros materiales misceláneos. Al realizar la ordenación y catalogación de todos los materiales de las "misiones" del antiguo Instituto Español de Musicología del CSIC (1944-1960), localicé este cuaderno y lo incorporé al nuevo archivador del Fondo de Música Tradicional IMF-CSIC, Misión M12: <https://musicatradicional.eu/source/130>.

${ }^{27}$ Por las cartas de presentación a Palmira Jaquetti que se conservan de la Misión M12, el nombre completo es Diego Ramírez Pastor, Diputado provincial de Barcelona, Ponente de Beneficencia; véase, más arriba, nota 13 .

${ }^{28}$ Francesc Pujol i Pons (Barcelona, 15-V-1878 - Barcelona, 24-XII-1945), compositor y director, fue durante muchos años subdirector, bibliotecario y archivero del Orfeó Català con Lluís Millet como director (al que sucedió en 1941). Pujol fue también responsable de la Obra del Cançoner Popular de Cata- mente a José Díaz, ${ }^{29}$ de la casa de Caridad, y a la cantora de las Hermanitas de la c[alle] de Caspe de quien hablo en su debido lugar.

Me duele que no se realicen esas pruebas. La mujer, también el hombre, valen la pena. Incluyo unas hojas escritas por los días de la misión a sus dos casas citadas en los días de abril 1945.

\section{[p. 4]}

También obtuve cartas de presentación del Ayuntamiento por mediación del Sr. Barón de Esponellas. ${ }^{30}$

En esas palabras he querido resumir muchas horas de espera, de introducción a despachos y a personas perplejas tanto de mi demanda como de su imposibilidad de presentarme con eficacia y sin herir susceptibilidades religiosas que ya me habían asegurado no tener nada que hacer allí (en determinada institución adonde forzosamente me había dirigido), mostrándome la puerta.

Rotos esos hielos he encontrado ya cierto agrado en recibirme y buena ayuda en facilitar mi labor.

Empecé por la Casa de Caridad [p. 5] y Hermanitas de los Pobres c[alle] Caspe. Entre los hombres de la primera casa hay dos viejecitos llamados Díaz, uno cocinero en su vida por el mundo, el otro el más dicharachero andaluz que darse pueda. Han cantado mucho. Me esperaban ya de un día para otro con algo nuevo, especialmente el cocinero, menos soñador, con su pequeña barbilla, su aureola blanca y su caballerosidad.

El otro Díaz, que es como un tío-vivo, como peonza inquieta, le saca chiste a su brazo paralítico hasta que la hermana no puede por menos que reñirle mientras escapa en su risa, como cogida en pecado.

lunya, impulsada por el mecenazgo de Rafael Patxot i Jubert (1872-1964, y colaboró con el Instituto Español de Musicología-CSIC clasificando y elaborando índices temáticos de las canciones recogidas en este centro hasta 1945.

29 José Díaz Sanz-Gil, natural de Madrid y de 75 años, había participado en la Guerra de Cuba y viajó por diversos países de Latinoamérica como cocinero. Véase su ficha en el siguiente enlace: $\quad<$ https://musicatradicional.eu/informant/1231>.

30 Epifani de Fortuny i Salazar (Barcelona, 1898 - Barcelona, 1989), arqueólogo e ingeniero, heredó de su padre Carles de Fortuny i de Miralles (1872-1931) la baronía de Esponellà. En 1944 el alcalde de Barcelona, Miquel Mateu i Pla, le nombró teniente de alcalde y presidente de la Ponencia de Beneficencia, ocupándose posteriormente de la sección deportiva. 
Todas las canciones del Díaz andaluz deberían fonografiarse. Es una fuente [p. 6] viva de salmodias y melodías y las canta muy bien. Se conduele continuamente de su juventud perdida, pero no tiene por ello menos sal. Su tono suave y su canto en sordina resultan, quizás, mejores sin congestionamiento ni voceos.

Por lo que toca a las mujeres, no ha habido cantoras que me ocuparan tanto, pero he recogido las jotas de Hipólita, una navarra, y los cantos y jotas de una cieguecita que recuerdo haber conocido en mi niñez, cantadora callejera, pequeña, suave, dulce, poquita cosa, con los ojos cerrados que no miran a ninguna parte, eternamente hundidos en sus órbitas. En el ojo derecho tiene una perla [p. 7] negra que le arrastra del párpado. No nació ciega. Un médico de aldea le trató los ojos con nitrato de plata y quedó con vida y manos para cegar otras víctimas el mediquillo. Pero Angelina ${ }^{31}$ hubo de sumirse en un sepulcro de tinieblas y de miseria que le ha dado la calle como nodriza y mentora, el asilo como premio final. Sus canciones pertenecen casi todas a la más absurda expresión de plebeyismo y decadencia. Todos los couplets están representados en su memoria-archivo. Todas las barbaridades musicales fueron servidas por ella a boca de jarro, a la puerta del mercado, donde las cándidas muchachitas de servicio aprenden su repertorio. Ella goza detallando esa felicidad [p. 8] suya, que se vertía en canto, como a la sombra de un árbol, bajo la copiosa frondosidad de las guitarras y bandurrias que la coreaban y que acompañaban su pobre alma, el alma que presentía vagamente su cielo.

En lugar tan poblado es bien raro encontrar tan pocos cantores. Pero aunque hay alguna otra mujer, no puedo reseñar nada de importancia.

En el As[ilo] Hermanitas P[obres] C[alle] Caspe me fue muy difícil introducirme. Llegué a apelar al Sr. Obispo, pero los buenos oficios intercesores del Rvdo D. Higinio Anglés suavizaron las asperezas y ya no fue necesaria la visita al Sr. Obispo. [p. 9] No obstante, después de un par de meses de trabajar se me anunció que debía cesar y que los hombres no habían de ser interrogados. En este forzoso interregno he depositado la paz. Pero intento romper filas y llegar a mi intrincada meta.

Muchas mujeres me han entregado su pequeño tesoro de canciones. Entre ellas una pequeña mujercita con cara de niña [espacio dejado en blanco, tal vez para el

31 Ángela Agudo Pintado, de 70 años, natural de Burgos, había residido en Figueres, l'Estartit y Barcelona; véase su ficha en el enlace: $<$ https://musicatradicional.eu/informant/221>. nombre], que canta maravillosamente y esconde sus años en un gracejo que la cubre como el fleco del mantón de algo cambiante y divino y así la devuelve a la niñez. Sus canciones deberían ser fonografiadas. En algunas escapa a ritmo y a pentagrama, en una continua creación [p. 10] juguetona y alegre como un cascabel.

He copiado en el costurero, en una mesa llena de alfileres. En el comedor, sumergido en el olor eterno de las grasas y estofados. En la fregadera, visitada por todos los cubos de la casa; los sábados en la enfermería, donde la vida declina sobre blancas almohadas y los sillones se invalidan a fuerza de sostener la invalidez.

No había terminado con [espacio en blanco, seguramente para insertar luego el nombre de la informante], y además había descubierto otra mujer que sabía cantar canciones sencillas y apetecibles. Es bueno, con esas ancianas asiladas, someterse a sus horas y reglamentos y dejarlas [p. 11] descansar y refrescar memoria.

Ellas y todas, aunque no canten, agradecen vivamente mi presencia y me hacen objeto de tierna ansiedad si en el día fijado no acudo. Me esperan. Ansían mi llegada. Se alimentan un poco de esa gran novedad.

La última vez estuve en el patio, donde se mondaban las patatas. La ocupación de las manos deja el espíritu libre y la memoria expedita y eso y su reposo es lo [que] me favorece y aprovecho.

Conseguir la entrada en las Hermanitas de Gracia también fue ardua empresa. Se me quiso convencer de la inutilidad de mi empeño y repetidas las aclaraciones y situada mi personalidad fui admitida en el seno de aquel nuevo hogar, [p. 12] pero sólo por una vez. No diré que he corrido, sino que mi pluma, que a menudo corre, volaba con mi cerebro como en peligro de muerte. Me fueron ofrecidas las mujeres tenidas por aptas para el canto pero yo no pude investigar nada. Por ello algunas veces he tomado y no sólo en esta ocasión, canciones que hubiera rehusado. Porque los hielos han de romperse con el mayor cuidado para que toda la masa no se quiebre. Alguna cosa sin importancia y en catalán procede de esta búsqueda tan forzada.

Mis cartas de presentación para esas tres (me falta aún hablar de las Hermanitas de la c[alle] de Borrell) instituciones me fueron facilitadas a requerimiento mío por el Ayuntamiento y [p. 13] Gobernación, pues esos establecimientos tienen vida autónoma y no son regidos por ningún Estatuto corporativo.

Sugiero algo que creo de interés: estaría muy bien y perfectamente aplicada una pequeña donación o limosna a las Hermanitas de los Podres. Eso ablandaría el corazón de 
las que aún me faltan en su mitad hombres y cuyo acceso he de volver a intentar, después del tiempo pasado y que prudentemente he dejado amontonar. Tengo que añadir que la decisión absurda y conminadora de cesar en el mismo día en que me fue dada la orden obedeció a las necesarias preguntas de edad nombre y condición con que llenar mi ficha. Y quiero aún consignar, aunque inmodestamente, mi amabilidad y conocimiento del mundo, [p. 14] de los niños y de los viejos, y mi falta de curiosidad, aunque soy mujer. Con ello quiero significar la ausencia de otras preguntas y otros intereses más que los que se me encomendaron. Es más: casi nunca lleno la ficha sino al cabo de una o dos canciones, para no ser brusca y llevar las preguntas con los elogios de lo que acabo de apuntar.

Paso ahora al Asilo de Ntra. Señora de Port, situado camino del delta del Llobregat, detrás del Cementerio Nuevo.

Con mi presentación por el Ayuntamiento toda puerta se abrió y toda facilidad me fue dada.

He visto y sentido mucho y honradamente en esos lugares donde la miseria acumula sus trofeos. Llagas en el [p. 15] alma y en el cuerpo aquejan a los infortunados pobres. Se pueden apurar los cálices del dolor y de una sola vez gustar muchos sufrimientos.

El Asilo de Port ofrece cambios continuos. No recibe a sus clientes para morir, sino como en un albergue, como un brazo hospitalario que cobija por un tiempo. Por ello he encontrado lo mejor en ese Asilo.

Rosa Lefler, ${ }^{32}$ mujer todavía en el uso de sus fuerzas, gran cantarina, bordadora de oficio, ha venido a parar aquí y sus cantos a mis cuadernos. Es un tesoro de añoranza, de simplicidad popular, de pretérita felicidad. Cantó y aprendió todo cuanto oía junto a su máquina de bordar. Cantó y vivió su juventud.

Ahora ha cantado a la fuerza y se ha [p. 16] hecho un momento feliz en su gran desolación. Le he pagado algo. Vuelve a recordar. Y durante muchos días Rosa Lefler ha llenado mis cuadernos.

Me llevé un bocadillo y trabajé todo el día, muchos días del pasado verano, en el alejado Asilo de Port.

Además ha cantado otra mujercilla casi ciega, y otras y otras sin la importancia y novedad de cantos avileños como la Lefler.

${ }^{32}$ Rosa Lefler Herradura, natural de Candeleda (Ávila), de 49 años, cantó 33 piezas a Palmira Jaquetti; véase el enlace: $<$ https://musicatradicional.eu/informant/2358>.
Los hombres no llegaron a poder cantar. No sabían ni cantaban canto ninguno.

Otra institución de la más grande importancia y que a mi entender debería ser visitada periódicamente es la Maternidad. Allí he acudido, [p. 17] día tras día, a oir canciones bien cantadas, con un punto de melancolía y un oído ausente. La nueva madre está siempre pendiente de la voz lejana del hijo, que la llama como la misma conciencia, y ese clima da a su canción un hálito singular.

Además, a la Maternidad acuden muchachas venidas de todas partes y algunas muy cultas. Ha sido tan fecunda la labor junto a esas pobres muchachas pálidas y tristes, que insisto en proponer que la tarea del Colector sea periódicamente renovada.

Con todo ello, son pocos los hombres y más, muchas más las mujeres cantoras. Pero queda todavía un filón no explotado. Esa beta inédita es [p. 18] la Cárcel, donde hombres y mujeres en el perfecto ejercicio de su memoria están relativamente inactivos y por ello en perfecto estado de memoria, y lo que es más, inclinados a confiar al canto sus miserias.

Incluyo algunas cartas que no me fueron de utilidad, obtenidas en mi trabajo preliminar. Esos asilos fueron consultados por mí y me dijeron no tener más que niños o incapacitados. Intenté aún el Manicomio. Pero aparte aquellos hombres como sombras de hombre, que pasean con un guía delante porque no saben querer ni la más mínima voluntad de obrar rige sus almas, [p. 19] no fue hallado ningún recluso con talante ni facultades cantoras, a pesar de mi valimiento en la caza.

El Asilo del Parque, donde se me ha dado toda clase de facilidades, me procuró ancianas dejadas ya de manos de la vida, marchitas, sin memoria, apagadas y pétreas. Pero en alguna permanecía ese tesoro acumulado con los años y la memoria, como salvada de múltiples naufragios, permanecía fiel. Ese es el caso de Victoria, ${ }^{33}$ que visitaba con mucha frecuencia para darle tiempo a recordar. Ha sido incansable, buena, sufrida. Fue persona pudiente, con tienda puesta en barrio muy denso y popular. Recogió toda canción oída, toda letra y cuarteta, toda basura. [p. 20] Y con tanto material, poco cuesta levantar lo mejor y dejar la paja.

\footnotetext{
${ }^{33}$ Se refiere a Victoria Sáenz Garijo, de 86 años, natural de Cervera del Río Alhama (La Rioja), aunque llevaba viviendo 60 años en Barcelona. Proporcionó a Palmira Jaquetti 176 piezas, aunque de muchas de ellas solo el texto; véase el enlace: <https://musicatradicional.eu/informant/3985>.
} 
Creo que sería eficiente la continuación en algunas de las casas ya exploradas, pero especialmente la C[asa de la] Maternidad, donde por desgracia acuden, una tras otras, cándidas palomas que en su desgracia, aún apetecen cantar y que ponen consuelo y beben ternura en el canto.

He ido despacio, porque saqué mejor partido, con las viejecitas de los Asilos. He ido mucho más [p. 21] deprisa, con las pobres muchachas de 1 [a] C[asa de la]
Maternidad. He pasado allí días enteros, aprovechando esa sed, esa ansia de maravilloso, mantenida y alimentada por sus enormes desencantos, que se adormece y se perpetúa en el canto.

Es todo.

Palmira Jaquetti

$1945-46$

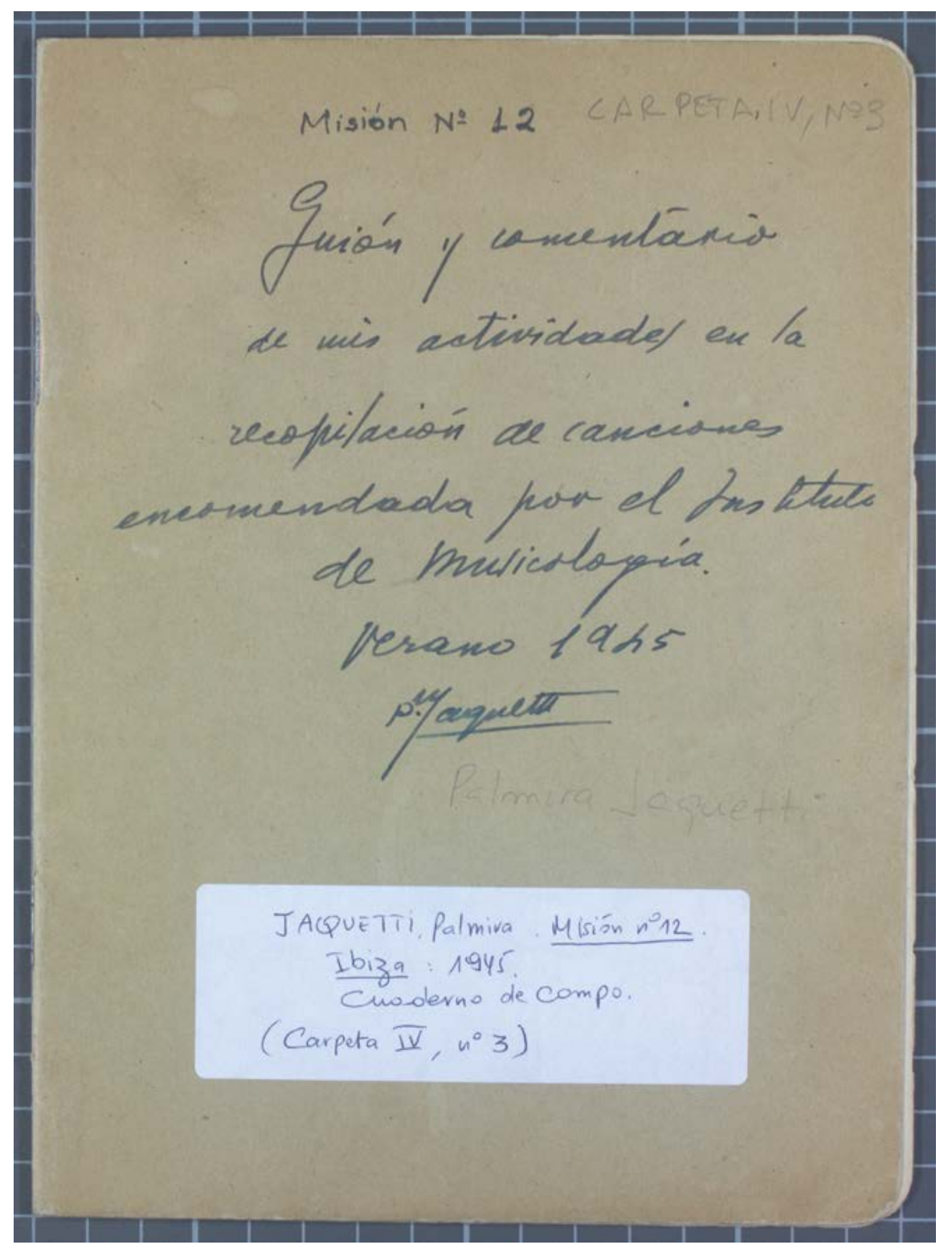

Figura 1. Cuaderno de campo de Palmira Jaquetti de la Misión M12 (Barcelona, 1945), tapa. 


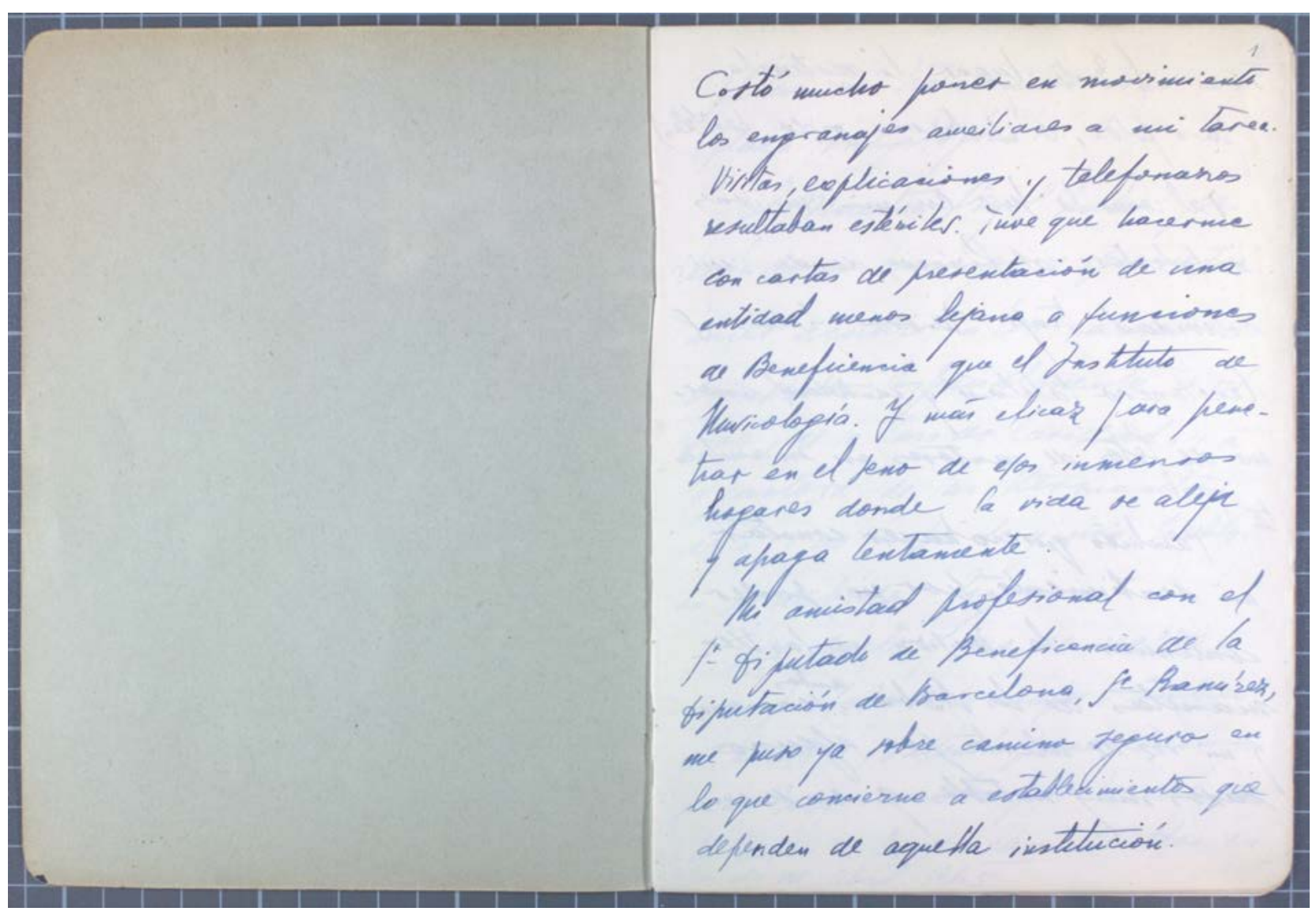

Figura 2. Cuaderno de campo de Palmira Jaquetti de la Misión M12 (Barcelona, 1945), p. 1.

\section{BIBLIOGRAFÍA CITADA}

“Actividades del Instituto Español de Musicología". Anuario Musical, 1 (1946), pp. 239-240.

Furey, Simon. "Palmira Jaquetti i Isant, Catalan folk song collector (1895-1963)". Estudos de Literatura Oral, 13-14 (2007-2008), pp. 159-174.

Grassot Radresa, Marta. "Cartes per recordar. Palmira Jaquetti i la recerca musical de camp". Revista Musical Catalana, 17 d'abril de 2020. <http://www.revistamusical.cat/cartes-per-recordar-palmira-jaquetti-i-la-recerca-musical-de-camp/>.

Jaquetti, Palmira. L'estel dins la llar. Barcelona: Edicions Oasi, 1938.

- Mis canciones. Barcelona: Juventud, 1943.

- Roda de Nadals. Barcelona: Studium, 1949.

- Trenta cançons nadalenques per a cant $i$ piano harmonitzades. Barcelona: J. García Gelabert, 1952.
- Cançons de caramelles per a chor d'homes, quartet vocal o chor mixte a dues, tres i quatre veus. Barcelona: J. García Gelabert, 1953.

—. Goigs de Sant Pelegrí Arties. Lletra i música. Barcelona: Obradors Gràfics Mariano Galve, 1953.

- Selección de canciones navideñas: originales y populares, dos cuadernos. Barcelona: J. Parés, 1954 y 1955 .

. Himnos. [Barcelona:] J. M. Parés, s.f.

. "La comptina". En Atti dell'VIII Congresso Internazionale di Studi Romanzi. Firenze, 3-8 aprile 1956. Firenze: Sansoni, 1960, vol. 2, pp. 567-599.

. "Contribution à la syntaxe de l'aranais". En Actas do IX Congresso Internacional de Linguística Românica (Universidade de Lisboa 1959), editado por Manuel Lopes de Almeida. Lisboa: Centro de Estudos Filológicos, 1961, pp. 377-393. 
."Apport à l'hydronoymie du Val d'Aran". En VI. Internationaler Kongress für Namenforschung (München, 24.- 28. August 1958), vol 3, editado por Gerhard Rohlfs i Karl Puchner. Munich: Verlag der Bayerischen Akademie der Wissenschaften in Kommission, 1961, pp. 437-443.

—. Poema de Santa Llúcia. Barcelona: Edición de la autora, 1961.

Massot i Muntaner, Josep, ed. Materials de l'Obra del Cançoner Popular de Catalunya, 21 vols. Barcelona: Fundació Rabell i Cibils y Publicacions de l'Abadia de Montserrat, 1926-2011. La edición de los cuadernos de campo de las misiones realizadas por Palmira Jaquetti se encuentran en los volúmenes $6,7,9,10,11,12,14,16$ y 20.

-. "Noves aportacions a l'Obra del Cançoner Popular de Catalunya". En A la ciutat dels llibres, tercera sèrie. Barcelona: Publicacions de l'Abadia de Montserrat, 2019, pp. 61-74.

Matheu, Roser. Quatre dones catalanes. Barcelona: Fundació Salvador Vives Casajuana, 1972.

Musset, Alfred de. Carmosina, traducción de Palmira Jaquetti. Barcelona: Biblioteca Popular de "L'Avenç", 1926.

_. La nit veneciana, traducción de Palmira Jaquetti. Barcelona: Biblioteca Popular de "L'Avenç", 1926.

Nerval, Gérard de. Jemmy, traducción de Palmira Jaquetti. La Novel-la Estrangera, 18 Valls: E. Castells, [1925?].

- Emilia. La mà encantada, traducción de P[almira Jaquetti]. La Novel-la Estrangera 28. [Valls]: E. Castells, [1925].

Pujol, Francesc. "Clasificación de las melodías populares. Metodología”. Anuario Musical, 1 (1946), pp. 19-29.
Roma, Josefina. "La dona en les cançons tradicionals a la Ribagorça”. Ripacurtia, 3 (2005), pp. 85-108.

_. "Palmira Jaquetti y la investigación del folklore musical". Temas de Antropología Aragonesa, 18 (2011), pp. 195-210.

_ _ "La descoberta de la música tradicional del Pirineu. Palmira Jaquetti i l'obra del Cançoner Popular de Catalunya". Annals del Centre d'Estudis Comarcals del Ripollès / Íbix 7. Ripoll: Centre d'Estudis del Ripollès, 2012, pp. 231-237: <https://www.raco.cat/ index.php/AnnalsCER/article/view/261991>

Ros-Fábregas, Emilio y Ascensión Mazuela-Anguita. "MISIÓN M12". Fondo de Música Tradicional $I M F-C S I C$, ed. E. Ros-Fábregas, <https://musicatradicional.eu/source/130>.

Ros-Fábregas, Emilio. "Capacidad transformadora de las Humanidades Digitales en el ámbito de la Musicología: las plataformas digitales de la IMF-CSIC Fondo de Música Tradicional y Books of Hispanic Polyphony". En Musicología en web. Patrimonio Musical y Humanidades Digitales, editado por María Gembero-Ustárroz y Emilio Ros-Fábregas. Kassel: Reichenberger, en prensa.

Selecta de poetes medievals, traducción de Palmira Jaquetti. Barcelona: Biblioteca Popular de "L'Avenç", 1926.

Subirats Bayego, Maria dels Àngels, Josefina Roma, Salvador Rebés, Joan de la Creu Godoy Tomás. "Palmira Jaquetti”. Revista d'Etnologia de Catalunya, 21 (2002), p. 168.

Recibido: 01.06.2020

Aceptado: 25.11.2020 